\title{
Germany debates future of research centres
}

Munich. Many of Germany's 16 national research centres are to appoint more industrialists to their policy-making committees in response to a report commissioned by the research minister, Paul Krüger, published last June. The centres may also see core government funding for some of their programmes cut by half.

But the report, based on a year-long study by an industry-orientated committee chaired by Hartmut Weule, head of the research division of Daimler-Benz, has opened up a fierce debate about how much say industry should have in controlling the future directions of national research efforts.

The report focused in particular on the activities of two of Germany's largest national research centres, the Forschungszentrum Jülich, known as the KfA, and the Kernforschungszentrum Karlsruhe, or KfK.

These two centres were established in the 1950 s to develop Germany's nuclear energy technology, and have since evolved into interdisciplinary research centres. But along with the other national research centres, which absorb 70 per cent of the research ministry's budget, they have recently come under attack for the alleged inflexibility of their research programmes (see Nature 363, 292; 1993).

The report made a series of recommendations on how the centres could become more useful to industry, the most controver- sial of which was the suggestion that the proportion of applied research carried out at the two centres should be increased from 30 per cent to 75 per cent within five years.

This caused an immediate outcry from the centres themselves, as well as from Germany's major research organizations such as the Max Planck Society and the Deutscheforschungsgemeinschaft (DFG), which funds university research projects.

These organizations were relieved that the recommendation was rejected by the ministry of research as "unrealistic". But the ministry is taking two other recommendations of the report more seriously. These concern the restructuring of the centres' research-policy-making committees and the way their funds are allocated.

The ministry has asked all national research centres that carry out a significant amount of applied research to increase the proportion of industrialists on their scientific advisory committees to around 50 per cent from next year. These committees, which advise the decision-making supervisory boards of the national research centres, tend to consist of academics in the main.

The ministry has also said that there should be an increase in representation of industryfrom around a quarter to around a third - on the supervisory boards themselves. How much extra control this will give industry over the direction of research is not yet

\section{UK labs to stay in public ownership}

London. David Hunt, Britain's minister for science, announced last week that the government had decided against privatizing the Daresbury and Rutherford Appleton Labo ratories (DRAL), the main central research facilities for UK universities.

The two laboratories, jointly run by the Science and Engineering Research Council until 1 April of this year, will become an independent body operating within the Office of Public Service and Science.

"Daresbury and Rutherford are national assets." Hunt said in announcing his decision. "I believe that according them independent status is the right way to proceed. but with strong emphasis on operating in a commercial manner, and particularly meeting the needs of customers."

The future of the DRAL had been up in the air ever since the government decided to carry out a study of whether it should remain a public body. Earlier this year. Britain's Royal Society, together with a number of other bodies, warned the government against any effort to turn the joint organization of the two laboratories into a private institution (see Nature. 368, 382; 1994)

Their message was reinforced by a report prepared by consultants KPMG. which told the government that the services provided by DRAL were widely appreciated by the scientific community. both in Britain and overseas, and that privatization would not represent a sensible option. It suggested that DRAL should become a "non-departmental pub lic body"

The government now appears to have accepted this advice. Its move was welcomed by the Royal Society, which issued a statement emphasizing that the government needs to ensure that DRAL continues to provide "vital support for members of the scientific community, irrespective of their sources of funding."

Under the new arrangements, the chief executive of the DRAL will have the same reporting relationship to the Director General of Research Councils as the heads of the six research councils. The budget of DRAL will be made up of a combination of core funding and money received directly from its 'customers'. The precise balance between the two has yet to be determined.

David Dickson clear. Satisfaction with the system depends on two possibly conflicting factors. All agree that industrial representation should be of a high quality. But the ministry spokesman, Mannfred Dietrich, says that to ensure that the best people from industry are prepared to devote time to the centres, they should be confident that their recommendations will have a strong chance of being adopted.

But Joachim Treusch, the director of $\mathrm{KfA}$, who has already created slots in his centre's advisory subcommittee for industrial representatives, says that industry's needs should not dominate the research agenda.

Paul Krüger, who remains acting research minister until Germany's new cabinet is announced later this month, insists that no programme will be imposed on the centres by industry without the general support of their research scientists.

The ministry is also debating the report's recommendation that up to half of its core funding for some programmes at the centres, particularly those identified as being close to the market, should be cut, to be made up through competitive grants or industrial contracts.

The questions of who should decide which projects fall into this category, and where scientists should turn for the top-up funds, are currently under discussion. But Dietrich confirms that the ministry wants the change to be implemented within four years.

With no sign of more money on the horizon, Germany's scientific community is worried that throwing national research centres into competition for ever-tightening research grants and shrinking industrial research funds will be damaging.

Karl-Heinz Hoffmann, head of Germany's science council, the Wissenschaftsrat, which advises the government on research issues, says that a move from core funding to a reliance on competitive grants from government-funded research programmes would be "unthinkable" without an increase in general funding for such programmes.

The two new national research centres in the new Länder, for molecular medicine at Berlin-Buch and for environmental research at Leipzig, were both intended to rely more heavily on competitive grants than their western counterparts. But they have not been as successful in attracting money as predicted, he says, as there is not enough to go round.

How the discussions develop will depend on the shape of the new government. The so-called 'holy alliance' - the Max Planck Society, the DFG, the national research centres, the university rectors conference, the Fraunhofer Society and the Wissenschaftsrat - are meeting Krüger this week to discuss the research policy of the next government. The policy of the research centres will be at the top of their agenda. 